\title{
A escada negra para o protagonismo branco: comédia, melodrama e retórica racial em A Dupla do Barulho (1953)
}

Pedro Vinicius Asterito Lapera

\section{Resumo}

Através da análise da cadeia produtiva de $A$ Dupla do Barulho (Carlos Manga, 1953) e de sua inserção no debate sobre relações raciais, o presente artigo tem como escopo as seguintes questões: em que medida a retórica racial encenada em A Dupla do Barulho dialoga com 0 momento de sua projeção e com as expectativas de seu público? E, como consequência da primeira pergunta, como o filme apresenta identidades racializadas na construção de hierarquias e gostos difundidos pela cultura massiva? Procuramos confirmar nossa hipótese de que o filme apresenta ao espectador uma narrativa cujas ligações entre comédia e melodrama reforçam o ideal de branqueamento, que se faz presente de modo difuso em diversos produtos da cultura de massa.

\section{Palavras-Chave}

Cinema brasileiro. Raça. Etnicidade.

A Dupla do Barulho.

\section{Pedro Vinicius Asterito Lapera}

I plapera@gmail.com

Doutor em Comunicação pela Universidade Federal Fluminense - UFF. Pesquisador vinculado ao Núcleo de Pesquisa da Fundação Biblioteca Nacional (FBN/Minc)

\section{Introdução}

Na peça Maria, escrita nos anos 1930, Isaac

Bábel narrou o drama da assimilação dos judeus à sociedade russa, pelo comércio e pelo casamento. A dimensão trágica deste processo é retratada a partir do malogro do casamento dos protagonistas (que nem chega a ser concretizado) e pela falência de um comerciante judeu, o qual se envolve amorosamente com uma russa filha de um coronel czarista que aderiu aos ideais revolucionários do movimento de 1917. A retórica racial depreciativa a respeito do papel dos judeus na Rússia não teria sido superada nem mesmo pela dimensão igualitária pregada pelos líderes da Revolução.

Guardadas as inúmeras diferenças, é possível estabelecer uma analogia entre 0 tom de Maria e 0 de algumas obras literárias, teatrais e cinematográficas que abordam a integração da população negra à sociedade pós-republicana no Brasil. A ideia da existência de um grupo étnico profundamente estigmatizado por diversas correntes intelectuais e tido como incapaz 
de ser incorporado ao convívio social de seus contemporâneos pode ser vista como uma ponte possível entre a narrativa exposta em Maria e outras que pretenderam lidar com as tensões em torno das práticas de segregação e hierarquização dos negros com 0 advento da República.

Dentro deste vasto panorama, podemos destacar o filme A Dupla do Barulho, produzido pela Atlântida Cinematográfica e exibido ao longo de 1953. A estreia do diretor Carlos Manga no cinema revelava sua intenção de fazer humor dialogando com temas já consolidados no panorama intelectual da época. A Dupla... mostrou-se a única chanchada que abordou diretamente 0 preconceito racial, embora não seja a única produção da Atlântida a fazê-lo. Em meados de 1949, José Carlos Burle dirigiu Também Somos Irmãos, porém o filme apresentava uma representação mais dramática, não podendo ser considerado uma chanchada.

Contrastando com o fracasso de bilheteria do filme de Burle - tal como Melo (2006) o expõe -, o filme de Manga fez sucesso perante o público, o que pode ser comprovado pelos folhetos de divulgação dos cinemas e pelos artigos sobre o filme na imprensa especializada em cinema, os quais testemunharam a presença da obra no circuito exibidor carioca por alguns meses.

Ambas abordaram a temática do preconceito racial em uma época que já tinha como referência para o pensamento social e as práticas cotidianas as noções de mestiçagem e de democracia racial, que exaltavam em diferentes campos (artes, política, entretenimento, etc.) a pluralidade étnica da população brasileira. Recordamos que esse movimento foi ganhando força nas duas décadas anteriores, mais precisamente com o projeto de nação do Estado Novo e de seus ideólogos, tais como Gilberto Freyre e Sérgio Buarque de Holanda.

Tendo em vista este panorama, 0 artigo tem como escopo as seguintes questões: em que medida a retórica racial encenada em $A$ Dupla do Barulho dialoga com o momento de sua projeção e com as expectativas de seu público? E, como consequência da primeira pergunta, como o filme apresenta identidades racializadas na construção de hierarquias e gostos difundidos pela cultura massiva? Dentro do afirmado por Ginzburg, de que "as crenças antigas não se dissolvem facilmente" (1988, p. 31), lançamos nossa hipótese: A Dupla do Barulho apresenta ao espectador uma narrativa cujas ligações entre comédia e melodrama reforçam o ideal de branqueamento, em torno das relações entre brancos e não brancos, defendido com ardor até algumas décadas antes da produção do filme (Skidmore, 1976) e que, embora em declínio de prestígio intelectual, marcava sua presença em narrativas veiculadas pela cultura massiva em momentos posteriores. 


\section{Humor, melodrama e trajetórias na construção de estigmas e hierarquias de raça}

Primeiramente, faz-se necessária uma pequena sinopse do enredo de A Dupla do Barulho. Tonico (Oscarito) e Tião (Grande Otelo) formam a dupla do título. Juntos, viajam por várias cidades apresentando esquetes cômicos, tendo sucesso com os espetáculos. A companhia é dirigida por Ricardo (Renato Restier), e suas viagens são acompanhadas por Sílvia (Edith Morel) e Maria (Mara Abranches). Em paralelo aos números cômicos, há várias expectativas amorosas não correspondidas: Sílvia mostra-se interessada por Tonico, que a trata mal; o mesmo valendo para Maria em relação a Tião. Nesse ponto, revelase crucial para 0 enredo a paixão platônica de Tião por Sílvia, uma vez que sua frustração é o ponto de virada na carreira do comediante e na narrativa do filme.

Em depoimentos posteriores, Carlos Manga relata que sua motivação inicial na escrita do roteiro e na direção de $A$ Dupla... foi a constante percepção de Otelo de que era sempre preterido perante 0scarito, com cachês menores e papéis que funcionavam como "escada" para 0 amigo: "Eu queria fazer um filme que tratasse do problema racial, mas Severiano Ribeiro Filho queria uma comédia, e o filme começa com scats muito engraçados e no meio fala do racismo, como eu queria"

Ironicamente, na própria apresentação do filme, repõe-se Otelo ao lugar do subalterno. Nos créditos iniciais, tendo como fundo a logomarca da empresa, eis a sequência: "Atlântida apresenta" / "Oscarito" / em "A Dupla do Barulho" / com "Grande Othelo" / depois nomes dos outros atores. 0 nome de 0scarito é colocado em destaque nos créditos, sendo evidenciado, portanto, como 0 ator principal da obra.

Frisando o fato de que a dupla Grande Otelo e Oscarito já era conhecida do público, por conta de vários filmes anteriormente exibidos, como a narrativa apresenta a dupla de comediantes ao espectador? Nos primeiros minutos do filme, Tião é o porta-voz do circo que anuncia o espetáculo do dia. Após ser abandonado por seu parceiro, Tonico fica desesperado e, a partir de uma ideia de Sílvia, constrange Tião fisicamente a entrar no palco com ele. Tião só entra em cena após ser forçado pelos seguranças do circo, que 0 agarram e 0 empurram até ali, sendo que a sensação de encurralamento de Tião é acentuada pelo emprego de vários planos médios rapidamente intercalados na montagem.

Em seguida, com o sucesso do público (que aplaudiu com entusiasmo o número improvisado), há um jantar para comemorar a formação da nova

Manga fala da chanchada em depoimento ao MIS [Museu da Imagem e do Som]. Rio de Janeiro: 0 Globo, 11 mar 1975. Conferir também o depoimento do diretor em AUGUSTO, Sérgio. Este mundo é um pandeiro: a chanchada de Getúlio a JK. São Paulo: Cia. das Letras, 2001, p. 131 e 192. 
dupla, no qual cabe a Tonico nomeá-la: "Ergo a

minha taça de catuaba para brindar a maior dupla deste país: Tonico e Tião".

Existem momentos em que 0 sucesso da dupla é apresentado na narrativa: por exemplo, na montagem, há uma sobreposição fotográfica com trilhos, placas de várias cidades e números de comédia de Tonico e Tião. Em um dos esquetes, o palco é filmado inteiro, e Sílvia aparece com vestido branco cantando e andando pela cena. Em seguida, Tião aparece de peruca loira, com o mesmo vestido, imitando os gestos de Sílvia de forma infantilizada. Tonico entra fantasiado de pinguim e flerta com Sílvia, que corresponde. Para sua frustração, o ‘Pinguim' troca-a por Tião travestido de mulher, sob a gargalhada do público.

Ao se debruçar sobre a obra de Rabelais e 0 riso popular medieval, Bakhtin (2008, p. 1-50) apresenta 0 problema de avaliar 0 aspecto cômico de uma cultura popular que já havia sido perdido graças à sátira moderna. Sobre o riso na modernidade, 0 autor salienta que este atua diretamente na construção das hierarquias sociais, legitimando, na maioria das vezes, 0 olhar dos dominantes. Tendo em vista uma separação entre 0 autor e 0 objeto do riso no mundo moderno, perde-se a dimensão integrada de uma cultura popular que, através do riso, invertia hierarquias e aproximava os sujeitos nos ritos populares.
No caso da dupla cômica, coube a Tonico

(Oscarito) cooptar à força o parceiro e nomeála após um sucesso inicial. Ainda, no esquete descrito, o duplo rebaixamento da personagem Tião (Grande Otelo) - pela feminilização e pela infantilização - é 0 alvo de sua comicidade, cabendo a Tonico o papel de agente na produção do riso. A dinâmica do referido esquete pode também ser considerada como um indício da ligação hierarquizada entre Tonico e Tião, cabendo ao primeiro o protagonismo cênico garantido pela centralidade do foco na câmera em sua personagem - e, no limite, também pode ser visto como um dado biográfico inserido na narrativa do filme no que se refere às relações entre 0scarito e Grande 0telo² (Augusto, 2001, p. 192). Em suma: à cisão entre sujeito e objeto do riso na modernidade, corresponde a posição hierárquica superior de Tonico/0scarito na dupla.

Além dos números cômicos, uma imaginação melodramática (Brooks, 1995) é acionada no espectador a partir de alguns desencontros amorosos e, posteriormente, do fracasso da carreira solo de Tião. Enquanto a comédia é responsável pela comunicação da dupla na cena pública, cabe a uma leitura melodramática situar os idílios amorosos privados das personagens. Por meio de informações dispostas ao longo da narrativa, o filme apresenta a paixão platônica de Tião por Sílvia. No primeiro encontro, ele lança 
olhares de admiração para Sílvia, os quais são realçados por um close up no rosto de Grande Otelo. Além disso, Tião defende Sílvia dos maustratos de Tonico, que, muitas vezes, a xinga e a humilha perante os outros integrantes da trupe. Ainda, frustra as investidas do Senhor Moreira (o 'mecenas' da companhia) em Sílvia, interrompendo abruptamente vários diálogos entre as personagens.

0 ponto de virada na narrativa de A Dupla... é a frustração das expectativas afetivas de Tião perante Sílvia. Tião é mostrado em close espionando uma troca de confidências entre Sílvia e Maria no camarim da trupe. Maria revela a Sílvia que é apaixonada por Tião, mas não é correspondida. Ao comentário de Sílvia de que deveria investir em Tião, Maria revela que ele é apaixonado por ela, daí sua tristeza. Sílvia reage desdenhando da percepção de Maria: "Mas que coisa ridícula e sem sentido!". A câmera retorna para o close em Tião, que aparece chorando e sob uma trilha sonora dramática.

Na sequência seguinte, Ricardo bate no camarim e pergunta por Tião. Após um período de busca, Tião aparece completamente embriagado e é carregado por Ricardo e os dois discutem: "Você não vale nada sem o Tonico, nada! Você está pensando o quê, seu moleque?". Tião, em um momento de catarse, revela o seu descontentamento diante de Tonico, Sílvia e Maria: "Tô cansado de ser explorado, não quero ser escada de ninguém! Não existe Tonico e
Tião". Tião vai embora cabisbaixo e carregado por Maria, sem olhar para Tonico e para Sílvia.

A crítica elegeu esse ponto como central da trama. Uma crítica sem autoria definida, publicada na edição de 13.08.1953 do jornal $O$ Popular, assim se referiu ao trabalho do diretor: "0 Sr. Carlos Manga devia estar alcoolizado quando aceitou 0 posto de diretor de um filme, cujo enredo é uma verdadeira catástrofe e representa mesmo um recuo de cerca de dez anos em matéria de senso artístico". Em seguida, adota um tom racista para rechaçar uma possível união entre Tião e Sílvia:

"essa do Grande Othelo, preto como carvão, representar o papel de um sujeito apaixonado pela ariana Edith Morel é de pasmar e, nas horas mais trágicas, provoca gostosas gargalhadas da plateia que não chega a compreender, realmente a que tipo de filme está assistindo" [grifo meu].

Mesmo com a carga racista, é interessante considerar que a crítica percebeu a encenação de uma barreira racial à concretização do romance entre Tião e Sílvia. Tal fato também foi destacado pela crítica de J. A. Bello, publicada em 13.08.1953 no jornal 0 Radical, que, com um tom mais condescendente, elogia 0 talento dramático de Otelo e se refere a seu papel desse modo: "os autores do argumento não esqueceram, porém, de lhe dar um toque sentimental. 0 amor do negrinho Tião pela linda e branquíssima estrela da companhia é perfeitamente humano e comovente. E o desespero do negro, natural e compreensível" [grifos meus]. 
Em geral, as críticas encontradas foram elogiosas quanto à atuação de Otelo, reconhecido como o principal ator no filme. Ainda, destacouse a diferença entre esse papel e outros já desempenhados por ele. Edmundo Lys, crítico de o Globo, ressaltou que

(...) 0 filme possibilitou tanto a Oscarito, como a Otelo, a demonstração de um legítimo histrionismo que, até agora, não havia sido aproveitado. Principalmente Otelo ganhou muito com esta película que Ihe possibilitou a demonstração de um insuspeitado talento dramático, fora do caricatural que the impõem sempre os diretores de cinema ${ }^{3}$.

No filme, a responsabilidade da ruptura da dupla recai sobre Tião. Vários planos de inserção mostram capas de jornais com títulos como "Abandonou o palco na estreia", e, com uma voz off de um locutor de rádio, anuncia a decisão de Tião desfazer a dupla. Em seguida, a narrativa mostra em várias sequências o sucesso de Tonico em oposição aos contínuos fracassos de Tião.

Tonico é mostrado em um set de filmagem vestido de fauno e, em seguida, a manchete: "Tonico no cinema". Um locutor de rádio diz: "Enquanto Tonico estreia no cinema, Tião dá provas de sua irresponsabilidade profissional. De empresário em empresário, joga fora as últimas chances de sua carreira". Novamente, uma reportagem aparece em um plano de inserção com o título "Tonico, o Novo Ídolo cômico do cinema", noticiando uma cerimônia de premiação na qual Tonico, retratado em um plano conjunto que 0 destaca, é ovacionado.

0 uso de oposições para situar trajetórias remete a uma leitura melodramática das ações sociais e pode ser visto como uma resposta estética e emocional à instabilidade das posições sociais na modernidade (Singer, 2000). Dessa forma, além de ser uma chave de leitura para o mundo privado da companhia e de seus integrantes, uma imaginação melodramática também é acionada de modo a construir as diferentes carreiras artísticas solo dos comediantes. É possível sublinhar que 0 filme situa os meios de comunicação massiva (notadamente 0 cinema e o rádio) como agentes estruturantes de carreiras artísticas, isto é, que atuam na produção de hierarquias sociais (e, no caso em questão, racial), configurando mais um dado autobiográfico presente na narrativa.

Mais um jornal estampa uma manchete favorável a Tonico: "Tonico volta aos teatros". Match cut do plano do jornal para Tião, que 0 amassa com raiva e 0 atira longe. Visivelmente bêbado, Tião quebra 0 camarim. Os jornais impressos não deixariam de condená-lo, e várias reportagens abordando seu comportamento agressivo aparecem em planos de inserção: "Embriagado, brigou com a estrela". Finalmente, a imagemsíntese do fracasso de Tião é a do mural do 
teatro Glória, na qual uma foto do espetáculo de Tião é removida por uma mão anônima.

0 contraste em torno das carreiras de Tonico e Tião pode ser interpretado como a dimensão pedagógica (Bhabha, 2005) do olhar melodramático, uma vez que seria uma punição à revolta de Tião quanto ao seu lugar social. É possível interpretar também que a atitude de Tião e a reação provocada por ela operam metonimicamente em relação à posição dos negros na sociedade brasileira. Se as estratégias cômicas hierarquizam racialmente, caberá às estratégias melodramáticas ratificar a visão de mundo conservadora. Assim, o comediante negro é reposto ao seu lugar social de subalterno, e a narrativa explora no espectador o medo de alterar bruscamente - pela revolta - posições sociais.

Isso é ainda mais evidenciado no desenlace da trama. Após muita insistência de Sílvia, Ricardo resolve aceitar Tião de volta à companhia. A última sequência é o espetáculo que recepciona 0 comediante. Panorâmica do teatro, onde Ricardo diz no palco: "Foi anunciada uma surpresa para esta noite. E é chegado o grande momento em apresentá-lo. Fico muito feliz em devolver a nosso público um verdadeiro artista, roubado por algum tempo do convívio de nossos palcos. Devemos apoiá-lo nesse momento tão crítico de sua carreira. Esqueçamos o passado e olhemos para 0 futuro! Devolvo-lhes... Tião!"

Câmera volta-se para o público, que se mostra estupefato. Tião, em um primeiro momento sorridente, recolhe-se ante a reação negativa do público, representada pelo silêncio. Close mostra Tonico estarrecido na plateia. Diante do silêncio, Tonico começa a aplaudi-lo, estimulando o público que, aos poucos, começa a imitá-lo. Todos levantam-se para aplaudir Tião.

Tião discursa: "Obrigado! Muito obrigado! Não deveria pedir mais nada depois do que acabo de receber. Creio que estou vivendo um dos maiores momentos da minha vida. No entanto, queria pedir apenas uma coisa: que compartilhe desse instante aquele a quem devo toda a minha carreira". Close de Tonico chorando na plateia. "Nada mais justo que hoje aproveite a oportunidade para trazer ao palco um companheiro de tanto tempo: Tonico. Tonico!" Ricardo, Sílvia e Maria aplaudem. Tonico levanta-se e o público aplaude. Tonico caminha em direção ao palco, finge um tropeço e cai nos braços de Tião.

Finalmente, Ricardo ordena ao maestro que toque música do número de Tonico e Tião, que o encenam. A união amorosa é sacramentada pelos gestos de Tião e de Tonico, que jogam beijos para Maria e Sílvia - respectivamente -, que os retribuem. 0 final apaziguador das oposições revela a manutenção da hierarquia na dupla. Cabe a Tonico o gesto benevolente do perdão, publicamente representado pelo aplauso, pelo incentivo ao público a aplaudi-lo e, por fim, 0 retorno glorioso à dupla. Assim, a vitória moral de Tonico corresponde à conciliação das oposições entre sucesso versus fracasso, salvação versus 
sofrimento e seu principal impacto no campo artístico: fama versus ostracismo. Por essa leitura, o espectador conclui que a dimensão performativa (Bhabha, 2005) da revolta de Tião - marcada pela denúncia da exploração de fundo racial, 0 que configura um indício de conflito diante da narrativa da nação em torno da integração racial - é enquadrada melodramaticamente como má, tida como capaz de perturbar a ordem social e, por isso, punida ao longo da narrativa.

Além dos entrelaçamentos entre comédia e melodrama na performance das hierarquias raciais mobilizadas pelo filme, precisamos compreender também de que modos A Dupla... relacionou-se com um conjunto de retóricas raciais historicamente articuladas nos debates, nas práticas e nos produtos veiculados pela comunicação massiva. Para tanto, passemos à outra parte deste artigo.

\section{Performances de papéis sociais e práticas artísticas: identidades $\mathrm{e}$ discursos raciais "à brasileira"}

Sobre A Dupla do Barulho, a historiografia do cinema brasileiro que 0 aborda no contexto da produção e da recepção das chanchadas (Augusto, 2001; Stam, 2008) tende a ratificar a leitura de Carlos Manga sobre 0 filme, destacando 0 aspecto de ineditismo do tema nas chanchadas e, por isso, valorizando positivamente a obra. Enquanto

Stam é mais sutil em seu argumento, limitandose a descrever 0 enredo do filme e a reproduzir 0 depoimento de Manga, Augusto claramente adere à interpretação do diretor, ao afirmar

ainda que amiúde the coubesse a honra de ser o mais safo da dupla, Otelo se angustiava com sua posição subalterna, fruto, a seu ver, de uma deformação de fundo racista. Carlos Manga explorou essa mágoa do ator em $A$ Dupla do Barulho, uma comédia à clef cheia de lances melodramáticos. Daquela vez, aliás, o deus ex machina foi o personagem de Oscarito, que tirava da sarjeta 0 antigo companheiro de palco (2001, p. 192) [grifo meu]

Como já defendemos em nossa análise da última sequência do filme, a 'salvação' da personagem de Otelo pela de 0scarito no filme está bem longe de ser uma solução Deus ex machina; ao contrário, os conflitos afetivos e profissionais que os conduziram a esse desenlace nos parecem bastante ancorados em práticas sociais e artísticas historicamente reificadas ${ }^{4}$.

Com um tom mais crítico, Carvalho (2006) destaca em sua análise sobre o filme a dimensão conservadora de sua narrativa: "Tião é penalizado por não saber o seu lugar: apaixonou-se pela mulher branca e contestou a ordem natural do espetáculo, 0 sucesso. Não falta sequer a representação estereotipada do negro como desprovido de razão adulta, moleque, etc." (2006, p. 73).

Sérgio Cabral, o biógrafo de Grande Otelo, praticamente desdenha do filme, dedicando-Ihe apenas um parágrafo em seu livro de quase trezentas páginas sobre 0 artista. Para nós, tal fato mostrou-se no mínimo curioso, visto que 0 autor discutiu aberta e extensamente a questão racial em sua trajetória. 
Isso nos conduz ao segundo ponto deste artigo, ou seja, a necessidade de verificar os modos pelos quais o filme relaciona-se com práticas discursivas ligadas à raça e à etnicidade já consolidadas no panorama intelectual brasileiro até a época de sua produção e recepção, dentro da perspectiva delineada por Guimarães de que "no nível do senso comum, a desmoralização da ideia de raça [que acontecia no meio acadêmico dos anos $1940 \mathrm{e}$ 50] não significará o fim imediato dos estereótipos que atingiam a população negra” (2002, p. 145).

Primeiramente, é preciso considerar que as palavras branco e negro não são mencionadas em nenhum momento do filme, não havendo tampouco situações que envolvam insultos raciais. 0 horizonte de expectativas em torno das leituras do público sobre a temática racial é construído pelo diretor a partir da fama da dupla de atores, que já havia realizado alguns filmes com grande sucesso comercial até então. Aliado a isso, a tentativa de Manga em abordar o tema adotou como ponto de partida um ressentimento de Otelo, segundo sua percepção.

Como já avaliamos, o filme desenvolve a performance da questão racial na narrativa a partir do fracasso da expectativa amorosa de Tião com relação a Sílvia e da oposição das trajetórias profissionais de Tonico e de Tião após o fim da dupla. Doris Sommer (2004) percebeu nas relações inter-raciais/interétnicas uma fonte importante para a representação do amor nas ficções de fundação, ou seja, nos romances do século 19 que encenam uma suposta origem das nações na América Latina.

No caso brasileiro, esses romances tenderam a privilegiar como protagonistas homens brancos e mulheres indígenas e negras, ofuscando, para isso, 0 aspecto de dominação étnica advinda a partir da colonização. Em A Dupla do Barulho, há uma inversão e, por conseguinte, a representação do romance inter-racial pelos seus polos silenciados: o homem negro e a mulher branca.

Sobre o papel ativo de Tião em imaginar e projetar o romance inter-racial, precisamos recordar a discussão de Schwarcz (1987; 2005) sobre 0 'perigo negro'. A autora avalia em sua pesquisa a imagem teratológica construída pela imprensa de circulação corrente do final do século 19 em confluência com 0 debate acadêmico sobre raça à época que era veiculado pelos editoriais de algumas publicações.

Dois aspectos de sua avaliação interessamnos aqui: a qualificação das massas de negros recém-libertos legalmente como perigosas e, mais especificamente, a percepção do homem negro como uma potencial ameaça às mulheres brancas e, portanto, à reprodução do corpo de uma nação que pretendia tornar-se branca, ideia encampada por alguns intelectuais que defendiam 0 combate à miscigenação como política de Estado.

Sobre o primeiro aspecto, este é fundamental para compreender os estigmas pelos quais a população 
negra foi vista de modo mais contundente a partir do início do regime republicano. À ocupação do espaço público por ex-escravos, correspondeu a visão de que seu ócio era fruto de vadiagem e fonte para delitos leves e graves e, por isso, sua presença deveria ser paulatinamente apagada. De fato, isso foi levado a cabo pelas reformas urbanas do início do século 20 em várias cidades brasileiras, pautadas pela racionalidade e pelo cientificismo caro à época. Nas palavras de Schwarcz,

negros, africanos, trabalhadores escravos e ex-escravos - 'classes perigosas' a partir de então - nas palavras de Romero transformavam-se em 'objetos de sciencia' (prefácio a [Raimundo Nina] Rodrigues, 1933/88). Era a partir da ciência que se reconheciam diferenças e se determinavam inferioridades (2005, p. 28)

Com relação ao segundo aspecto, a condenação ao contato inter-racial remete-se principalmente ao controle da sexualidade da mulher branca. Assim, retornando ao romance (não concretizado) de Tião e Sílvia, a ridicularização feita pela atriz sobre essa possibilidade na conversa com Maria pode ser lida como o sucesso desse controle.

Já verificamos na parte anterior que a revolta de Tião após a desilusão amorosa configura a encenação de uma barreira racial. Tal fato chocase frontalmente contra a retórica da mestiçagem que, segundo Guimarães, é uma consequência da ideia de democracia racial, uma síntese das ideias difundidas por Gilberto Freyre (2002, p. 141-144). Contrariando a ideia de encontros inter-raciais assimilacionistas e apaziguadores, o conflito estabelecido por Tião desafiou a hierarquia no ambiente artístico e questionou a não integração do negro nas relações afetivas. Isto é, a performance de Tião retoma a ideia do 'perigo negro' tanto no mundo privado quanto no público na narrativa de $A$ Dupla... .

Nesse momento, reconhecemos que as identidades racializadas precisam ser analisadas tendo em mente a mediação operada pela obra através do entrecruzamento entre melodrama e comédia. Debruçando-se sobre as narrativas pautadas pelo excesso, Baltar considera que

a construção de uma expressividade visual forte é uma das características fundamentais do excesso, elemento que se consolida como estratégico para a articulação de uma pedagogia das sensações, que se configura em resposta à sensibilidade geral forjada no contexto da formação da subjetividade moderna (2012, p. 131-132).

Diante do argumento da autora, podemos inferir que A Dupla... pretende apresentar ao espectador uma pedagogia das sensações orientada a performances de papéis sociais e de uma hierarquia racial que, embora difusa, faz-se presente no cotidiano e, por conseguinte, nas práticas artísticas.

Ao retomarmos alguns elementos da última sequência do filme, é possível verificar como o engajamento do espectador é acionado pela narrativa. Nela, cabe a Tonico o papel ativo na redenção de Tião, que só se torna possível através de seu intermédio. A construção da expectativa 
dá-se pelo silêncio dos espectadores, seguido da focalização de Tonico e é seu aplauso constante que desencadeia a reação positiva do público.

Diante disso, Tião faz o discurso da conciliação e recordamos seu ápice: "Nada mais justo que hoje aproveite a oportunidade para trazer ao palco um companheiro de tanto tempo: Tonico. Tonico!"

Trata-se da legitimação de uma integração da população negra - porém, uma integração hierarquizada - e da capitulação do sentimento de revolta (e, por dedução, da possibilidade de transformação social decorrida dele). Repõe-se 0 conflito às posições inicialmente ocupadas pelos comediantes. Desse modo, a narrativa, ao explorar 0 excesso (pelo riso e pelas lágrimas), evidencia a união entre 0 pacifismo caro à retórica da mestiçagem e a centralidade do branco postulada pelo ideal de branqueamento. Com isso, produz uma pedagogia das sensações que pretende incutir no espectador a manutenção da ordem e dos papéis sociais dominantes e subalternos, mais precisamente a quem cabe exercer cada papel. Seguindo este raciocínio, é preciso ater-se ao detalhe de que 0 ato das mulheres em jogar os beijos (Sílvia para Tonico; Maria para Tião) acentua a manutenção dessa hierarquia racial, projetando-a no mundo privado.

Ao analisar a performance desses papéis sociais, devemos destacar uma característica que perpassa as personas dos comediantes no filme: ambos são mostrados alcoolizados em diferentes momentos na narrativa. Curiosamente, aparecem bêbados três vezes. Na cena em que Tonico 'batiza' a dupla, sua embriaguez é o mote da discussão com Sílvia que, ao pedir que ele pare de beber, é humilhada publicamente pelo comediante. Em outras duas sequências, essa embriaguez opera como 0 elemento que desencadeia peripécias cômicas caras à chanchada. Destacamos que todas as sequências em que isso acontece são passadas antes do fim da dupla.

Por sua vez, a embriaguez de Tião é mostrada tardiamente, sendo que, no ponto de virada do filme, isto é, na cena em que há a discussão entre 0 comediante e 0 diretor da companhia ela funciona como motor de sua catarse, quando se rebela contra sua exploração. Além disso, aparece em dois momentos posteriores à ruptura da dupla. Ao ver uma reportagem elogiosa a Tonico, Tião é focado ao lado de uma garrafa de cachaça segurando um copo, atirando-o em seguida e amassando com raiva o jornal. Por fim, na sequência em que Tião passa mal e cai na rua, encontra-se visivelmente alcoolizado, o que é percebido pelos gestos cambaleantes e pela alucinação que precede 0 desmaio.

Enquanto 0 alcoolismo é mostrado apenas como um elemento pitoresco da personalidade de Tonico, não gerando grandes consequências para sua carreira, opera melodramaticamente como uma justificativa moral para 0 ostracismo de Tião, agindo no sentido de punir seu sentimento de revolta e retomando a ideia do 'perigo negro', na qual o homem negro era representado como 
avesso ao trabalho e potencialmente prejudicial à manutenção da ordem.

Ainda, recordamos que o diretor da companhia refere-se a Tião como ‘vagabundo' no diálogo com Sílvia, quando esta vai pedi-lo para que aceite 0 comediante de volta. Podemos deduzir disso que se trata da performance de estigmas (Goffman, 1975) que pairam sobre a população negra, tal como apresentado pelos intelectuais da virada dos séculos 19 e 20 que se pautaram pelas teorias raciais europeias (Schwarcz, 2005) e que moldou a construção de um senso comum a partir de sua veiculação por produtos caros à cultura massiva (jornais, filmes, charges, etc) ${ }^{5}$.

Por último, vejamos brevemente como algumas matérias veiculadas durante a exibição do filme nos cinemas cariocas abordaram os atores que interpretaram os protagonistas do filme. $\mathrm{Na}$ reportagem Onde se fala de Chaplin, Oscarito e Grande Otelo, publicada sobre o filme na edição de 02.08.1953 do jornal Diário Carioca, o crítico Montenegro Bentes exalta a figura do 0scarito na primeira parte do artigo, comparando-0 a Chaplin e elegendo-o como o maior cômico brasileiro. Em seguida, Bentes assim se refere a Grande Otelo: "Mas o que dizer de Grande Otelo, um negro que já nasceu artista? Também cada nação tem 0 seu grande artista negro, e o Brasil não podia deixar de apresentar um, que pode ser posto com vantagem ao lado de qualquer outro artista de qualquer outra nacionalidade" [grifos meus].

\section{Enquanto 0scarito aparece sem qualquer} marca étnica e com seu talento reconhecido em termos mais universais, inclusive apelandose a uma comparação com um ícone do cinema há muito consolidado, Grande Otelo é racialmente identificado e, nos termos do artigo, a sua posição subalterna perante 0scarito é reafirmada. No fundo, o elogio feito a ele 0 rebaixa hierarquicamente, em vez de colocá-lo em um plano de igualdade com o comediante branco.

No mesmo periódico, foi publicada uma entrevista com Edith Morel na edição de 07.06.1953, intitulada Nasci para dançar! Exclama Edith Morel, a nova estrela do cinema brasileiro e também realizada por Montenegro Bentes. Em linhas gerais, a entrevista, que ocupou duas páginas do periódico, pautou-se pela trajetória profissional da atriz, sobretudo pela sua carreira no teatro carioca e em filmes anteriores da Atlântida. Também trata do desempenho de Morel no filme e de sua relação cotidiana nos estúdios onde 0 filme foi gravado. Apenas em uma frase há menção a outra estrela feminina (Mara Abranches), a quem Bentes se refere como "uma ‘colored' que causará sensação”, transferindo a hierarquia feita entre os comediantes para as protagonistas femininas.

A título de exemplo, podemos citar a pesquisa de Carolina Vianna Dantas sobre Manoel Monteiro Lopes, o primeiro deputado negro eleito na Primeira República em 1909. Em várias charges veiculadas pelos jornais e revistas da época e coletadas pela autora, o deputado é representado como um homem negro alcoolizado. 


\section{Considerações Finais}

Ao contrário do debate acadêmico sobre raça, marcado por critérios racionais/científicos e formado a partir dos alinhamentos e das oposições entre diferentes correntes, a cultura de massa apresenta distintos elementos de modo não linear, assimétrico e mesclando temporalidades.

No caso em questão, a obra mostrou-se parcialmente conectada à retórica da mestiçagem e ao ideal de democracia racial, que, à época de sua produção e circulação, eram ideias legitimadas tanto academicamente quanto no plano da criação artística. Isso não impediu que ideias mais antigas sobre relações raciais - como 0 'perigo negro' e 0 ideal de branqueamento deixassem de aparecer na narrativa.

Aliás, embora o filme tenha tido a proposta inicial de abordar o tema do preconceito racial, tal fato não impediu que, na articulação entre humor e melodrama para expor e solucionar os conflitos, 0 ideal de branqueamento triunfasse como a retórica mais presente na narrativa, precisamente em sua produção de uma pedagogia das sensações orientada à manutenção dos lugares sociais tradicionalmente reservados a brancos e a negros. Isso nos leva a inferir que, mesmo com o declínio de seu prestígio acadêmico a partir dos anos 1930, o ideal de branqueamento pôde ressurgir em diversos produtos da cultura massiva, legitimando hierarquias sociais (nesse caso, racial).
Voltemos ao exemplo inicial da obra de Bábel.

Tanto nela quanto no filme que abordamos, a dimensão trágica reside justamente na impossibilidade do encontro, da concretização do afeto. E justamente por testemunhar essa dimensão trágica das relações inter-raciais, a análise de $A$ Dupla do Barulho revelou ser um interessante percurso intelectual.

\section{Referências}

AUGUSTO, Sérgio. Este mundo é um pandeiro: a chanchada de Getúlio a JK. São Paulo: Cia. das Letras, 2001.

BÁBEL, Isaac. Maria - uma peça e cinco histórias. São Paulo: Cosac Naify, 2003.

\section{BAKHTIN, Mikhail. A Cultura popular na Idade} Média e no Renascimento: o contexto de François Rabelais. São Paulo-Brasília: Hucitec-Unb, 2008.

BALTAR, Mariana. Tessituras do excesso: notas iniciais sobre o conceito e suas implicações tomando por base um Procedimento operacional padrão.

Revista Significação, USP, número 38, 2012, p. 124-146.

BHABHA, Homi. 0 Local da cultura. Belo Horizonte: Ed. UFMG, 2005.

BR00KS, Peter. The Melodramatic Imagination: Balzac, Henry James, Melodrama and the mode of excess. Yale University Press: London, 1995.

CABRAL, Sérgio. Grande Otelo: uma biografia. São Paulo: Editora 34, 2007.

CARVALHO, Noel. Cinema e representação racial: 0 cinema negro de Zózimo Bulbul. Tese de Doutorado em Sociologia apresentada à FFLCH-USP. São Paulo, 2006. Orientador: Prof. Dr. Antônio Sérgio Guimarães.

DANTAS, Carolina. A cor na política: a eleição de Monteiro Lopes para a Câmara dos Deputados em 1909. 
In: PEREZ, E. (org) Pesquisa na Biblioteca Nacional.

Rio de Janeiro: Fundação Biblioteca Nacional, 2010, p.

9-27.

GINZBURG, Carlo. Os andarilhos do bem: feitiçaria e cultos agrários nos séculos XVI e XVII. São Paulo: Cia. das Letras, 1988.

GOFFMAN, Erwin. Estigma: notas sobre a

manipulação da identidade deteriorada. Rio de Janeiro, Jorge Zahar, 1975.

GUIMARÃES, Antônio Sérgio Alfredo. Classes, raças e democracia. São Paulo, Ed. 34, 2002.

MACHADO, Hilda. Oscarito, Grande Otelo e a negação do amor. Revista Alceu, Puc-Rio, v.8, n. 15 jul/dez 2007, p. 60-68.

MELO, Luis Alberto Rocha. Argumento e roteiro: o escritor de cinema Alinor Azevedo. Dissertação defendida junto ao PPGCOM-UFF. Niterói, 2006. Orientadora: Profa. Dra. Hilda Machado.

SCHWARCZ, Lilia Moritz. Retrato em branco e negro. São Paulo: Círculo do Livro, 1987. 0 Espetáculo das raças. São Paulo: Cia. das Letras, 2005.

SINGER, Ben. Melodrama and modernity. Columbia University Press: Nova York, 2000.

SKIDMORE, Thomas. 0 Brasil visto de fora. São Paulo, Paz e Terra, 1994.

Preto no branco: raça e nacionalidade no pensamento brasileiro. Rio de Janeiro, Paz e Terra, 1976.

SOMMER, Doris. Ficções de Fundação: os romances nacionais da América Latina. Belo Horizonte: Ed. UFMG, 2004.

STAM, Robert. Multiculturalismo tropical: uma história comparativa da raça na cultura e no cinema brasileiros. São Paulo: Edusp, 2008. 
Black stairs to White role: comedy, melodrama and racial rethoric in $A$ Dupla do Barulho (1953)

\section{Abstract}

By the analysis of the film A Dupla do Barulho (Carlos Manga, 1953) and its inclusion in the debate on race relations, this article intends to present some questions: to what extent the racial rhetoric staged in A Dupla do Barulho dialogues with the moment of its projection and with the expectations of its audience? As a result of the first question, how the film features identities in the construction of hierarchies and tastes disseminated by mass culture? We seek to confirm our hypothesis that the film presents to the spectator a narrative whose links between comedy and melodrama reinforce the ideal of whiteness, which is presented in a diffuse way in several mass culture products.

\section{Keywords}

Brazilian Cinema. Race. Ethnicity. A Dupla do Barulho.

\section{La escalera negra para el protagonismo blanco: comedia, melodrama y retórica racial en A Dupla do Barulho (1953)}

\section{Resumen}

A través del análisis de la película $A$ Dupla do Barulho (Carlos Manga, 1953) y su inclusión em el debate sobre relaciones raciales y étnicas, este artículo intenta presentar algunas preguntas: cómo la retórica racial escenada en A Dupla do Barulho dialoga con el momento de su proyección y con las expectativas de su público? Cómo la película presenta identidades raciales en la construcción de jerarquias y gustos propagados por la cultura massiva? Intentamos confirmar nuestra hipótesis: la película presenta al espectador una narrativa que salienta el ideal de blanqueo a partir de las conexiones entre comedia y melodrama.

\section{Palabras-Clave}

Cine brasileño. Raza. Etnicidade. A Dupla do Barulho. 


\section{Expediente}

A revista E-Compós é a publicação científica em formato eletrônico da Associação Nacional dos Programas de Pós-Graduação em Comunicação (Compós). Lançada em 2004, tem como principal finalidade difundir a produção acadêmica de pesquisadores da área de Comunicação, inseridos em instituições do Brasil e do exterior.

\section{E-COMPÓS I www.e-compos.org.br I E-ISSN 1808-2599}

Revista da Associação Nacional dos Programas

de Pós-Graduação em Comunicacão.

Brasília, v.17, n.3, set./dez. 2014

A identificação das edições, a partir de 2008

passa a ser volume anual com três números.

\section{CONSELHO EDITORIAL}

Afonso Albuquerque, Universidade Federal Fluminense, Brasil Alberto Carlos Augusto Klein, Universidade Estadual de Londrina, Brasil Alex Fernando Teixeira Primo, Universidade Federal do Rio Grande do Sul, Brasil Rio Grande do Sul, Brasi

Ana Gruszynski, Universidade Federal do Rio Grande do Sul, Brasil Ana Silvia Lopes Davi Médola, Universidade Estadual Paulista, Brasil André Luiz Martins Lemos, Universidade Federal da Bahia, Brasi Ângela Freire Prysthon, Universidade Federal de Pernambuco, Brasil Antônio Fausto Neto, Universidade do Vale do Rio dos Sinos, Brasil Antonio Carlos Hohlfeldt, Pontifícia Universidade Católica do Rio Grande do Sul, Brasil Antonio Roberto Chiachiri Filho, Faculdade Cásper Líbero, Brasi Arlindo Ribeiro Machado, Universidade de São Paulo, Brasil Arthur Autran Franco de Sá Neto, Universidade Federal de São Carlos, Brasil Benjamim Picado, Universidade Federal Fluminense, Brasil César Geraldo Guimarães, Universidade Federal de Minas Gerais, Brasil Cristiane Freitas Gutfreind, Pontifícia Universidade Católica do Rio Grande do Sul, Brasil Denilson Lopes, Universidade Federal do Rio de Janeiro, Brasil Denize Correa Araujo, Universidade Tuiuti do Paraná, Brasil Edilson Cazeloto, Universidade Paulista, Brasil

Eduardo Vicente, Universidade de São Paulo, Brasil

Eneus Trindade, Universidade de São Paulo, Brasil

Erick Felinto de Oliveira, Universidade do Estado do Rio de Janeiro, Brasil Florence Dravet, Universidade Católica de Brasilia, Brasil

Gelson Santana, Universidade Anhembi/Morumbi, Brasi Gilson Vieira Monteiro, Universidade Federal do Amazonas, Brasil Gislene da Silva, Universidade Federal de Santa Catarina, Brasil Guillermo Orozco Gómez, Universidad de Guadalajara, México Gustavo Daudt Fischer, Universidade do Vale do Rio dos Sinos, Brasil Hector Ospina, Universidad de Manizales, Colômbia Herom Vargas, Universidade Municipal de São Caetano do Sul, Brasil leda Tucherman, Universidade Federal do Rio de Janeiro, Brasil Inês Vitorino, Universidade Federal do Ceará, Brasil Janice Caiafa, Universidade Federal do Rio de Janeiro, Brasil Jay David Bolter, Georgia Institute of Technology, Estados Unidos Jeder Silveira Janotti Junior, Universidade Federal de Pernambuco, Brasi João Freire Filho, Universidade Federal do Rio de Janeiro, Brasil John DH Downing, University of Texas at Austin, Estados Unidos Ana Carolina Damboriarena Escosteguy, Pontifícia Universidade Católica do

José Afonso da Silva Junior, Universidade Federal de Pernambuco, Brasil José Carlos Rodrigues, Pontifícia Universidade Católica do Rio de Janeiro, Brasil José Luiz Aidar Prado, Pontifícia Universidade Católica de São Paulo, Brasil José Luiz Warren Jardim Gomes Braga, Universidade do Vale do Rio dos Sinos, Brasil Juremir Machado da Silva, Pontifícia Universidade Católica do Rio Grande do Sul, Brasil Laan Mendes Barros, Universidade Metodista de São Paulo, Brasi Lance Strate, Fordham University, USA, Estados Unidos Lorraine Leu, University of Bristol, Grã-Bretanha Lucia Leão, Pontifícia Universidade Católica de São Paulo, Brasil Luciana Panke, Universidade Federal do Paraná, Brasil Luiz Claudio Martino, Universidade de Brasília, Brasil Malena Segura Contrera, Universidade Paulista, Brasil Márcio de Vasconcellos Serelle, Pontifícia Universidade Católica de Minas Gerais, Brasil Maria Aparecida Baccega, Universidade de São Paulo e Escola Superior de Propaganda e Marketing, Brasi Maria das Graças Pinto Coelho, Universidade Federal do Rio Grande do Norte, Brasil Maria Immacolata Vassallo de Lopes, Universidade de São Paulo, Brasil Maria Luiza Martins de Mendonça, Universidade Federal de Goiás, Brasil Mauro de Souza Ventura, Universidade Estadual Paulista, Brasil Mauro Pereira Porto, Tulane University, Estados Unidos Nilda Aparecida Jacks, Universidade Federal do Rio Grande do Sul, Brasil Paulo Roberto Gibaldi Vaz, Universidade Federal do Rio de Janeiro, Brasil Potiguara Mendes Silveira Jr, Universidade Federal de Juiz de Fora, Brasil Renato Cordeiro Gomes, Pontifícia Universidade Católica do Rio de Janeiro, Brasil Robert K Logan, University of Toronto, Canadá

Ronaldo George Helal, Universidade do Estado do Rio de Janeiro, Brasil Rosana de Lima Soares, Universidade de São Paulo, Brasi Rose Melo Rocha, Escola Superior de Propaganda e Marketing, Brasil Rossana Reguillo, Instituto de Estudos Superiores do Ocidente, México Rousiley Celi Moreira Maia, Universidade Federal de Minas Gerais, Brasi Sebastião Carlos de Morais Squirra, Universidade Metodista de São Paulo, Brasil Sebastião Guilherme Albano da Costa, Universidade Federal do Rio Grande do Norte, Brasil

Simone Maria Andrade Pereira de Sá, Universidade Federal Fluminense, Brasi Suzete Venturelli, Universidade de Brasília, Brasil

Tiago Quiroga Fausto Neto, Universidade de Brasília, Brasil

Valerio Fuenzalida Fernández, Puc-Chile, Chile

Veneza Mayora Ronsini, Universidade Federal de Santa Maria, Brasi Vera Regina Veiga França, Universidade Federal de Minas Gerais, Brasil

\section{COMISSÃO EDITORIAL}

Cristiane Freitas Gutfreind I Pontifícia Universidade Católica do Rio Grande do Sul, Brasil Irene Machado I Universidade de São Paulo, Brasil

Jorge Cardoso Filho I Universidade Federal do Recôncavo da Bahia, Brasil Universidade Federal da Bahia, Brasil

CONSULTORES AD HOC

Adriana Amaral, Universidade do Vale do Rio dos Sinos, Brasil

Alexandre Rocha da Silva, Universidade Federal do Rio Grande do Sul, Brasi

Arthur Ituassu, Pontifícia Universidade Católica do Rio de Janeiro, Brasil

Bruno Souza Leal, Universidade Federal de Minas Gerais, Brasil

Elizabeth Bastos Duarte, Universidade Federal de Santa Maria, Brasil

Francisco Paulo Jamil Marques, Universidade Federal do Ceará, Brasi

Maurício Lissovsky, Universidade Federal do Rio de Janeiro, Brasil

Suzana Kilpp, Universidade do Vale do Rio dos Sinos, Brasil

Vander Casaqui, Escola Superior de Propaganda e Marketing, Brasi

EDIÇ̃̃O DE TEXTO E RESUMOS I Press Revisão

SECRETÁRIA EXECUTIVA I Helena Stigger

EDITORAÇÃo ELETRÔNICA I Roka Estúdio
COMPÓS I www.compos.org.br

Associação Nacional dos Programas de Pós-Graduação em Comunicação

Presidente

Eduardo Morettin

Universidade de São Paulo, Brasil

eduardomorettin@usp.br

Vice-presidente

Inês Vitorino

Universidade Federal do Ceará, Brasil

ines@ufc.br

Secretária-Geral

Gislene da Silva

Universidade Federal de Santa Catarina, Brasil

gislenedasilva@gmail.com 